\title{
Tracheoesophageal Fold
}

National Cancer Institute

\section{Source}

National Cancer Institute. Tracheoesophageal Fold. NCI Thesaurus. Code C34315.

Two longitudinal folds in the laryng otracheal diverticulum of the early embryo, which approach each other and fuse to form the tracheoesophageal septum. 